\title{
Physical activity and telomere length in early stage breast cancer survivors
}

\author{
Sheila N Garland ${ }^{1,2}$, Brad Johnson ${ }^{3}$, Christina Palmer ${ }^{1,4}$, Rebecca M Speck ${ }^{5,6}$, Michelle Donelson ${ }^{6}$, Sharon X Xie ${ }^{6}$, \\ Angela DeMichele ${ }^{2,6}$ and Jun J Mao $0^{1,2,6^{*}}$
}

\begin{abstract}
Introduction: Telomere length (TL) is a biomarker of accumulated cellular damage and human aging. Evidence in healthy populations suggests that TL is impacted by a host of psychosocial and lifestyle factors, including physical activity. This is the first study to evaluate the relationship between self-reported physical activity and telomere length in early stage breast cancer survivors.

Methods: A cross-sectional sample of 392 postmenopausal women with stage I-III breast cancer at an outpatient oncology clinic of a large university hospital completed questionnaires and provided a blood sample. TL was determined using terminal restriction fragment length analysis of genomic DNA isolated from peripheral blood mononuclear cells. Physical activity was dichotomized into two groups (none versus moderate to vigorous) using the International Physical Activity Questionnaire. Multivariate linear and logistic regression analyses were performed to identify factors associated with mean $T L$ and physical activity.
\end{abstract}

Results: Among participants, 66 (17\%) did not participate in any physical activity. In multivariate model adjusted for age, compared to those who participated in moderate to vigorous physical activity, women who participated in no physical activity had significantly shorter TL (adjusted coefficient $\beta=-0.22 ; 95 \%$ confidence interval (Cl), -0.41 to $-0.03 ; P=.03)$. Non-white race, lower education and depressive symptoms were associated with lack of self-reported physical activity $(P<0.05$ for all) but not TL.

Conclusion: Lack of physical activity is associated with shortened $\mathrm{TL}$, warranting prospective investigation of the potential role of physical activity on cellular aging in breast cancer survivors.

\section{Introduction}

Improvements in the diagnosis and treatment of breast cancer have created a cohort of breast cancer survivors now surpassing three million women [1]. Physical activity can help improve the long-term psychological and physical health of breast cancer survivors, and potentially reduce the risk of disease recurrence and mortality [2-4], but questions remain regarding the influence of physical activity on measures of health at a cellular level. Telomere length (TL) is increasingly being examined as a biomarker of accumulated cellular damage and human aging [5]. Telomeres are repetitive nucleoprotein structures on the

\footnotetext{
* Correspondence: jun.mao@uphs.upenn.edu

'Department of Family Medicine and Community Health, Perelman School of Medicine at the University of Pennsylvania, Philadelphia, PA 19104, USA

${ }^{2}$ Abramson Cancer Center, Perelman School of Medicine at the University of Pennsylvania, Philadelphia, PA 19104, USA

Full list of author information is available at the end of the article
}

end of chromosomes with the main purposes of maintaining genomic stability and protecting against unbridled cellular division. As the cell divides with time, TL progressively shortens until critically short telomeres eventually lead to cell death or senescence. The examination of TL holds promise for identifying behavioral and environmental factors that can promote health and recovery in the context of cancer.

Previous research has demonstrated that TL can be impacted by a host of lifestyle and psychosocial factors [6]. Specifically, emerging evidence suggest that physical activity and regular exercise may positively impact TL in healthy individuals [7]. A cross-sectional study of 44 postmenopausal women compared the TL of habitual exercisers to women with a sedentary lifestyle [8]. Habitual exercisers had significantly longer TL than sedentary women and, even after adjusting for covariates, habitual exercise accounted for $75 \%$ of the variance in TL. The impact of physical activity 
on TL has also been examined in terms of exercise energy expenditure. In a study of 69 men and women between the ages of 50 and 70 years, individuals reporting moderate levels of physical activity had longer TL than participants at the lower and higher ends of the energy expenditure spectrum [9]. Despite the emerging evidence that physical activity may have a positive impact on TL and the growing interest in survivorship programs that encourage breast cancer survivors to be more active, no study has evaluated the association between physical activity and cellular aging in breast cancer survivors.

This study aims to evaluate the association between self-reported physical activity and TL in a large crosssectional sample of postmenopausal breast cancer survivors. This examination is important as clinical outcomes in the context of breast cancer survivorship (for example, recurrence, cancer-specific mortality and overall mortality) are likely dependent on a complex interplay between cancer and host biology [2]. Identifying a biomarker that can be modified by behavioral approaches such as physical activities will further allow us to examine the specific mechanisms of physical activities underlying the potential positive effect on clinical outcomes. We hypothesized that those who were not participating in physical activity would have shorter telomeres than those who engaged in moderate to rigorous physical activity. As a secondary aim, we also sought to identify factors related to lack of physical activity in this population.

\section{Methods}

\section{Sample and setting}

We conducted a cross-sectional study of women with earlystage breast cancer between March 2008 and July 2009 at the Rowan Breast Cancer Center of the Abramson Cancer Center of the University of Pennsylvania (Philadelphia, PA, USA). The institutional review board of the University of Pennsylvania and the regulatory committee of the Abramson Cancer Center approved the study and all participants provided informed consent. Research assistants screened medical records and approached potential patients for enrollment at their regular follow-up appointments. After informed consent was obtained, each participant completed a self-administered survey and a blood sample was collected for telomere analysis. Patients were eligible for study inclusion if they were: 18 years or older; had a history of stage I, II, or III breast cancer; postmenopausal; currently or previously on aromatase inhibitors, and able to understand written English. The sample size in the original cross-sectional survey was 476 , reflecting a $78 \%$ response rate among those eligible. Complete physical activity and telomere data were available for 392 of those patients. There were no differences between our sample and the original sample in terms of age, race, or education.

\section{Measures}

\section{Primary outcome}

Telomere length was determined using mean terminal restriction fragment (TRF) lengths as described by Lorenzini et al. [10] with minor modifications. Five hundred nanograms of purified DNA isolated from peripheral blood mononuclear cells (PBMCs) were digested to completion with HinfI and RsaI. Digested samples and size markers ( ${ }^{32}$ P-end-labeled $1 \mathrm{~Kb}$ Plus DNA ladder and HindIII-cut lambda DNA) were separated in a $0.5 \%$ agarose gel. Within the gel, DNA was denatured under alkaline conditions, neutralized, and then hybridized with a ${ }^{32} \mathrm{P}$-end-labeled oligonucleotide (CCCTAA $)_{4}$ probe overnight at $55^{\circ} \mathrm{C}$. Blots were washed to remove non-specifically bound probe, and visualized using a PhosPhorImager (Molecular Dynamics Sunnyvale, CA). Mean TRF length was calculated as:

$$
\Sigma\left(\mathrm{OD}_{\mathrm{i}}\right) / \Sigma\left(\mathrm{OD}_{\mathrm{i}} / \mathrm{L}_{\mathrm{i}}\right)
$$

where $\mathrm{OD}_{\mathrm{i}}$ is the total radioactivity above background in interval $i$ and $L_{i}$ is the average length of $i$ in base pairs (bp). The genomic DNA was verified to be of high molecular weight by electrophoresing the undigested DNA samples on $0.5 \%$ agarose gels that were subsequently stained with ethidium bromide to show that $>99 \%$ of the DNA ran at limit-mobility.

\section{Primary exposure}

Physical activity was measured using the international physical activity questionnaire (IPAQ) [11]. The IPAQ is a self-administered 4-item questionnaire assessing the frequency and duration of moderate and vigorous intensity physical activity in the past seven days. Examples of moderate physical activity include brisk walking, bicycling, vacuuming, gardening, or anything else that causes some increase in breathing or heart rate. Vigorous physical activity includes running, aerobics, heavy yard work, or anything else that causes large increases in breathing or heart rate. The IPAQ has acceptable test-retest reliability and concurrent validity. Criterion validity has been adequately demonstrated when measured against accelerometry [11]. Similar to the methods reported in Puterman et al. [12] and Kim et al. [8], and considering the evidence for recall bias in physical activity measurement [13], we dichotomized physical activity into two groups based on habitual exercise levels (none versus moderate to vigorous).

\section{Covariates}

Patient-reported social demographic variables included age, body mass index (BMI), race/ethnicity, education level, and marital status. Clinical factors such as stage, chemotherapy treatment, current aromatase inhibitor use and comorbidities were obtained via chart abstraction. 
Table 1 Characteristics of participants

\begin{tabular}{|c|c|c|c|}
\hline & & Number & $\%$ \\
\hline & & 392 & 100 \\
\hline \multirow[t]{25}{*}{$\begin{array}{l}\text { Demographic } \\
\text { characteristics }\end{array}$} & $\begin{array}{l}\text { Age, years } \\
\text { (mean, 61.97; SD, 10.36) }\end{array}$ & & \\
\hline & $<55$ & 91 & 23.2 \\
\hline & 55 to 65 & 170 & 43.4 \\
\hline & $>65$ & 131 & 33.4 \\
\hline & BMI (mean, 27.21; SD, 5.85) & & \\
\hline & $<25$ & 163 & 41.6 \\
\hline & 25 to 30 & 123 & 31.4 \\
\hline & $>30$ & 106 & 27.0 \\
\hline & Smoking status & & \\
\hline & Never & 207 & 52.9 \\
\hline & Current & 13 & 3.3 \\
\hline & Previous & 171 & 43.7 \\
\hline & Race/ethnicity & & \\
\hline & White & 322 & 82.1 \\
\hline & Non-white* & 70 & 17.9 \\
\hline & Educational level & & \\
\hline & High school or less & 85 & 21.7 \\
\hline & College & 167 & 42.6 \\
\hline & Graduate or higher & 139 & 35.5 \\
\hline & Marital status & & \\
\hline & Married/partnered & 244 & 62.2 \\
\hline & Single & 136 & 34.7 \\
\hline & Physical activity & & \\
\hline & None & 66 & 16.8 \\
\hline & Moderate to vigorous & 326 & 83.2 \\
\hline \multirow{16}{*}{$\begin{array}{l}\text { Clinical } \\
\text { characteristics }\end{array}$} & Stage & & \\
\hline & 0 and $I$ & 154 & 39.3 \\
\hline & $\|$ & 192 & 49.0 \\
\hline & III & 46 & 11.7 \\
\hline & Previous chemotherapy & & \\
\hline & No chemotherapy & 153 & 39.0 \\
\hline & Chemotherapy & 239 & 61.0 \\
\hline & $\begin{array}{l}\text { Current aromatase } \\
\text { inhibitors }\end{array}$ & & \\
\hline & None & 41 & 10.5 \\
\hline & Letrozole & 67 & 17.1 \\
\hline & Anastrozole & 240 & 61.2 \\
\hline & Exemestane & 44 & 11.2 \\
\hline & Cormorbid conditions & & \\
\hline & None & 62 & 15.8 \\
\hline & One & 118 & 30.1 \\
\hline & Two or more & 212 & 54.1 \\
\hline
\end{tabular}

Table 1 Characteristics of participants (Continued)

\begin{tabular}{llll}
\hline Symptom profile & HADS anxiety & & \\
& Normal & 282 & 71.9 \\
& Symptomatic & 101 & 25.8 \\
HADS depression & & \\
$\quad$ Normal & 344 & 87.8 \\
Symptomatic & 34 & 8.7 \\
\hline
\end{tabular}

${ }^{*}$ Mostly Black; hospital anxiety and depression scale (HADS) categorization:

Normal $=0$ to 7 ; symptomatic $=8$ to 21 . BMI, body mass index.

The hospital anxiety and depression scale (HADS) was used to measure depression and anxiety symptoms. The HADS is a 14-item, self-rated instrument for anxiety (7 items) and depression (7 items) in the past week, and was developed for patients with chronic illnesses. Established cutoffs are: 0 to 7 , no significant depression/ anxiety; 8 to 10 , subclinical depression/anxiety; 11 to 21 , clinically significant levels of depression/anxiety. The HADS has been extensively used and validated and has demonstrated adequate sensitivity and specificity to detect cases of depression and anxiety in cancer patients [14,15].

\section{Analysis}

Descriptive statistics were performed for demographic characteristics, clinical variables and patient-reported psychological health. Telomere length was compared between physical activity groups using the independent samples $t$-test. Univariate linear regression analysis was performed to identify variables associated with TL. A series of univariate logistic regression was used to identify independent predictors of not engaging in physical activity. Covariates with $P$-values $<0.10$ in univariate analysis was carried forward to the respective multivariate model. Statistical tests were two-sided with $P<0.05$ indicating significance. All data were analyzed using STATA 12.0 (StataCorp, College Station, TX, USA). Given that our sample size was fixed at 392 and approximately $1 / 5$ of our sample was inactive, we were powered to detect a statistically significant difference of 0.356 of the standard deviation between the inactive and active groups with a two-sided significance of 0.05 , and $80 \%$ power.

\section{Results}

Participant characteristics

Table 1 shows the sociodemographic and disease characteristics for the 392 patients included in this study. The mean age of the women was 62 years (range $=33$ to 91). The majority of the women were white $(82 \%)$. Of the participants in the non-white category $(n=70)$, the majority of the women were Black/African (14\%) followed by Asian (2\%), Hispanic/Latino (1\%) and other (1\%). These categories were collapsed in subsequent analyses. Most of the women were married or partnered (62\%) 
and had either a college $(43 \%)$ or graduate education (36\%). The mean BMI for the sample was in the overweight category at 27.21 (range $=18.53$ to 63.47 ) with $27 \%$ in the obese range (BMI >30.00). The most common stages of breast cancer at diagnosis were stage I (39\%) and II (49\%) and $61 \%$ of the women had been treated with chemotherapy. The majority of the women were also taking an aromatase inhibitor, the most common of which was anastrozole $(61 \%)$. There were fewer respondents in the subclinical and clinical ranges of depression and anxiety; thus, the psychological variables were collapsed into normal and symptomatic categories to maximize statistical power. Roughly $1 / 4$ of women (26\%) reported problematic levels of anxiety while $9 \%$ of women endorsed significant levels of depressive symptoms. Mean TL in the whole sample was $6.07 \mathrm{~kb}$, (range $=3.28$ to 8.19).

\section{Physical inactivity and telomere length}

Among participants, $17 \%$ of women did not engage in physical activity. These participants had shorter TL compared to those who participated in moderate/vigorous physical activities (mean $5.84 \mathrm{~kb}$ versus $6.11 \mathrm{~kb}$; $t(390)=-2.757 ; P=0.006$, see Figure 1). Univariate and multivariate linear regression analyses examining the association between demographic, clinical and psychological variables and TL are presented in Table 2. In unadjusted analyses, compared to women who reported moderate to vigorous physical activity, women who did not report engaging in any physical activity had significantly shorter TL $(\beta=-0.27 ; 95 \% \mathrm{CI},-0.08$ to $-0.46 ; P=0.006)$. As expected TL progressively shortened with age, with significant differences observed when women older than 65 were compared to women below 55 years of age $(\beta=-0.33$; $95 \%$ $\mathrm{CI},-0.52$ to $-0.13 ; P=.001)$. Having had chemotherapy treatment was significantly associated with longer $\mathrm{TL}$ ( $\beta=0.19 ; 95 \% \mathrm{CI}, 0.04$ to $0.34 ; P=0.01$ ). In the multivariate regression model, lack of physical activity remained significantly associated with shorter TL (adjusted coefficient $(\operatorname{Adj} \beta)=-0.22 ; 95 \% \mathrm{CI},-0.41$ to $-0.03 ; P=0.03$ ), as did older age (<65) (Adj $\beta=-0.26$; $95 \% \mathrm{CI},-0.47$ to $0.04 ; P=.02$ ). Being treated with chemotherapy was no longer significant in the multivariate model.

\section{Factors associated with physical inactivity}

A logistic regression model was developed to identify factors related to lack of physical activity in this population (Table 3). The strongest predictors of not being physically active in the multivariate model were lower education, depressive symptoms, and self-identifying as a race other than white. Women with a college education were less likely to be physically inactive compared with women with an education level of high school or less (adjusted odds ratio $(\mathrm{AOR})=0.34 ; 95 \% \mathrm{CI}, 0.16$ to $0.70 ; P=0.003)$. This association was stronger for women with a graduate education or greater $(\mathrm{AOR}=0.20 ; 95 \% \mathrm{CI}, 0.08$ to 0.47 ; $P<0.001)$. Depressed participants were significantly more likely to report being physically inactive $(\mathrm{AOR}=4.57$; 95\% CI, 1.86 to $-11.25 ; P<0.0001)$, compared to those women without clinically significant depressive symptoms. Women who self-identified as non-white were more likely to be physically inactive than white women $(\mathrm{AOR}=2.29$; $95 \%$ CI, 1.07 to $4.90 ; P=0.03$ ).

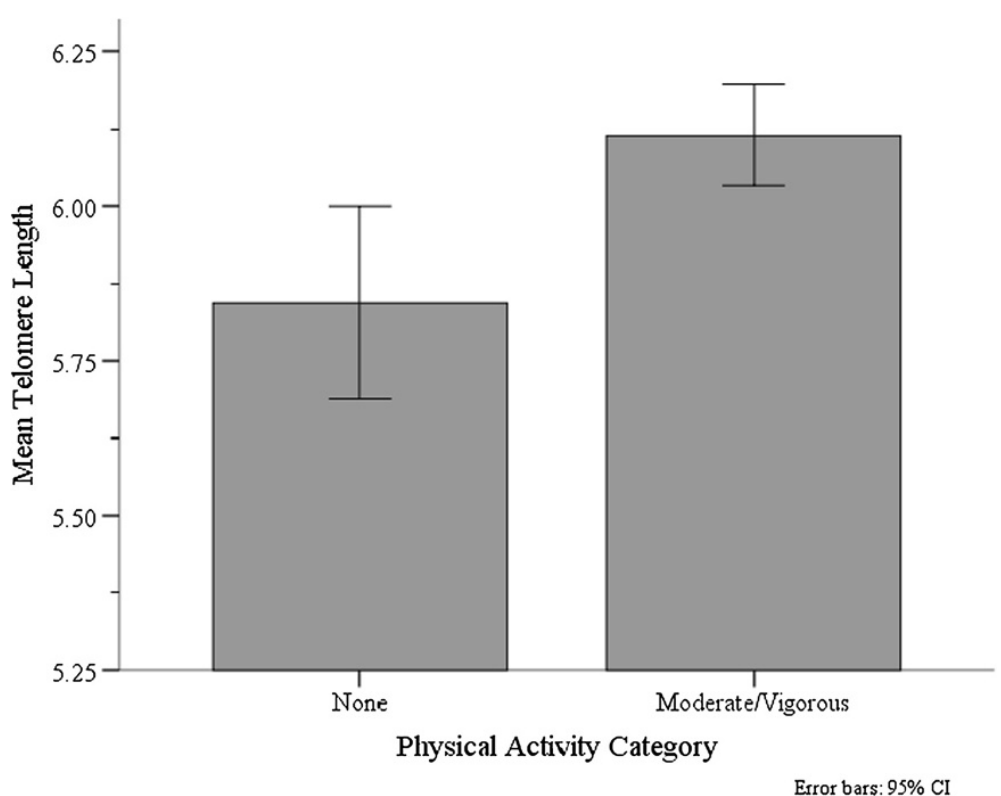

Figure 1 Unadjusted mean telomere length (TL, presented in kilobase pairs) in breast cancer survivors according to physical activity. No physical activity mean $\mathrm{TL}=5.84$ ( $\mathrm{SD}=0.63$ ); Moderate/vigorous physical activity mean $\mathrm{TL}=6.11$ (SD=0.75); $p=0.006$. 
Table 2 Linear regression of factors associated with telomere length

\begin{tabular}{|c|c|c|c|c|}
\hline & \multicolumn{2}{|l|}{ Univariate analysis } & \multicolumn{2}{|l|}{ Multivariate analysis } \\
\hline & Coefficient $(95 \% \mathrm{Cl})$ & $P$ & Adjusted coefficient $(95 \% \mathrm{Cl})$ & $P$ \\
\hline \multicolumn{5}{|l|}{ Physical activity } \\
\hline Moderate to vigorous (reference) & 1 & & 1 & \\
\hline None & $-0.27(-0.08,-0.46)$ & 0.006 & $-0.22(-0.41,-0.03)$ & 0.03 \\
\hline \multicolumn{5}{|l|}{ Age, years } \\
\hline$<55$ (reference) & 1 & & 1 & \\
\hline 55 to 65 & $-0.12(-0.30,0.07)$ & 0.22 & $-0.09(-0.28,0.10)$ & 0.33 \\
\hline$>65$ & $-0.33(-0.52,-0.13)$ & 0.001 & $-0.26(-0.47,0.04)$ & 0.02 \\
\hline
\end{tabular}

Body mass index
$<25$ (reference)
25 to 30
$>30$

\section{Smoking status}

Never (reference)

Current

Previous

\section{Race/ethnicity}

White (reference)

Non-white*

\section{Educational level}

$$
\begin{aligned}
& \text { High school or less (reference) } \\
& \text { College } \\
& \text { Graduate or higher }
\end{aligned}
$$

\section{Marital status}

Married/partnered (reference)

Single

\section{Stage}

0 and I (reference)

$\|$

III

\section{Previous chemotherapy}

No chemotherapy (reference)

Chemotherapy

Current aromatase inhibitor

None (reference)
Letrozole
Anastrozole
Exemestane

\section{Cormorbid conditions}

None (reference)

One

Two or more
1

$\begin{array}{ll}-0.01(-0.19,0.16) & 0.88\end{array}$

$-0.13(-0.031,0.05) \quad 0.16$

1

$-0.11(-0.52,0.30) \quad 0.60$

$-0.09(-0.24,0.06) \quad 0.22$

1

$-0.03(-0.22,0.16) \quad 0.74$

1

$0.07(-0.12,0.26) \quad 0.48$

$0.16(-0.04,0.36) \quad 0.11$

1

$-0.02(-0.18,0.13) \quad 0.76$

1

$0.04(-0.11,0.20) \quad 0.58$

$0.06(-0.18,0.31) \quad 0.60$

1

$0.19(0.04,0.34)$

0.01

$0.07(-0.09,0.24)$

0.38
1

$0.09(-0.19,0.38) \quad 0.53$

$-0.01(-0.26,0.23) \quad 0.93$

$0.03(-0.28,0.34) \quad 0.84$

1

$-0.02(-0.25,0.21) \quad 0.86$

$-0.11(-0.32,0.10) \quad 0.29$ 


\section{Table 2 Linear regression of factors associated with telomere length (Continued)}

\begin{tabular}{|c|c|c|}
\hline Anxiety & & \\
\hline Normal (reference) & 1 & \\
\hline Symptomatic & $-0.01(-0.18,0.16)$ & 0.93 \\
\hline Depression & & \\
\hline Normal (reference) & 1 & \\
\hline Symptomatic & $0.05(-0.21,0.31)$ & 0.70 \\
\hline
\end{tabular}

*Mostly Black; hospital anxiety and depression scale (HADS) anxiety and depression categorization: normal = 0 to 7; symptomatic $=8$ to 21 . Covariates with

$P$-values $<0.10$ in the univariate analyses were carried forward to the respective multivariate models. $P$-values in boldface type are statistically significant.

\section{Discussion}

In this study, we found an association between lack of physical activity and shorter TL in a large crosssectional sample of breast cancer survivors. Adjusting for the impact of age, women reporting no physical activity had significantly shorter TL than women who reported engaging in moderate to vigorous activity. The mean difference between women who were and were not physically active was $270 \mathrm{bp}$. Research by Slagboom et al. demonstrated that the average decrease in TL was 31 bp per year [16]. This suggests that, independent of age, more sedentary women may be close to 9 years biologically older than women who are more physically active, on a cellular level. To our knowledge, this is the first study to quantify the relationship between physical activity and TL in breast cancer survivors.

Telomere length measured from PBMCs reflects the cumulative effects of psychosocial, environmental and behavioral factors, as opposed to current health status, and is predictive of morbidity and mortality [17]. The presence of short TL in peripheral blood cells has been linked to age-related disease and preclinical conditions of diseases including increased mortality from cancer [18]. A recent longitudinal cohort study of 478 women with stage I to IIIa breast cancer examined PBMC TL change from 6 to 30 months post diagnosis [19]. Telomere shortening was associated with increased risk of all cause and breast cancer specific mortality, suggesting that change in blood TL over time could be a biomarker of prognosis. This finding is consistent with an earlier prospective 20-year study of 47,102 individuals suggesting that shorter TL is associated with reduced survival after all cancer diagnoses, including breast [20]. Based on existing research linking TL measured in PBMC and increased mortality from cancer, TL may represent an innovative biomarker to measure the status of host biology of aging; and as the host ages, its ability to perform immune surveillance may decrease, and thereby increase the probability of recurrence of metastasis.

Our finding of an association between physical activity and TL may provide an important opportunity to elucidate the mechanism of physical activity on health outcomes in cancer survivors. A recent systematic review of
17 studies examining the impact of physical activity on survival provides support for the role of physical activity in reducing all cause, and cancer specific, mortality in women with breast cancer [21]. This conclusion is echoed by a more generalizable systematic review of 45 studies in heterogeneous cancer populations, of which 13 were randomized and controlled trials [4]. It is possible that physical activity may buffer against the cellular aging process thereby protecting individuals from agingrelated diseases; however, the role of physical activity in this relationship remains to be demonstrated. While we know that physical activity reduces breast cancer risk, morbidity and mortality, prospective research is needed to determine whether physical activity may be an effective intervention to slow the rate of further telomere shortening or promote telomere recovery after cancer treatment.

Although the precise mechanisms are still unknown, physical activity is likely to influence telomere dynamics via the cumulative reduction in oxidative stress [22], DNA damage [23], and inflammation [24,25]. Initial research also suggests that a reduction in perceived stress may influence the association between exercise and TL [26,27]. Puterman et al. categorized 63 healthy postmenopausal women into two categories based on whether or not they met the daily recommended amount of physical activity [12]. In women who were more active, there was no association between perceived stress and TL whereas in sedentary women, a one-unit increase in perceived stress was related to a 15 -fold increase in the odds of having shorter telomeres. Preliminary research has also suggested that a stress reduction intervention may positively impact telomere length in a sample of cervical cancer survivors [28]. Although these results require replication, the modification of stress appraisals via physical activity may be a mechanism to improve health at a cellular level.

While our results support the potential benefit of physical activity on cellular aging for early stage breast cancer survivors, we also identified specific characteristics that if present reduce the likelihood of engaging in physical activity. Consistent with previous research, lower education was associated with not being physically 
Table 3 Logistic regression of factors associated with lack of physical activity

\begin{tabular}{|c|c|c|c|c|}
\hline & \multicolumn{2}{|c|}{ Univariate analysis } & \multicolumn{2}{|c|}{ Multivariate analysis } \\
\hline & OR $(95 \% \mathrm{Cl})$ & $P$ & AOR $(95 \% \mathrm{Cl})$ & $P$ \\
\hline \multicolumn{5}{|l|}{ Demographic characteristics } \\
\hline \multicolumn{5}{|l|}{ Age, years } \\
\hline$<55$ (reference) & 1 & & 1 & \\
\hline 55 to 65 & $1.33(0.61,2.92)$ & 0.48 & $0.96(0.38,2.41)$ & 0.91 \\
\hline$>65$ & $2.62(1.21,5.65)$ & 0.01 & $1.44(0.52,4.00)$ & 0.48 \\
\hline \multicolumn{5}{|l|}{ BMI } \\
\hline$<25$ (reference) & 1 & & 1 & \\
\hline 25 to 30 & $1.47(0.74,2.94)$ & 0.27 & $1.32(0.59,2.91)$ & 0.50 \\
\hline$>30$ & $3.03(1.58,5.81)$ & $<0.001$ & $1.93(0.88,4.23)$ & 0.10 \\
\hline \multicolumn{5}{|l|}{ Race/ethnicity } \\
\hline White (reference) & 1 & & 1 & \\
\hline Non-white* & $3.81(2.11,6.86)$ & $<0.001$ & $2.29(1.07,4.90)$ & 0.03 \\
\hline \multicolumn{5}{|l|}{ Educational level } \\
\hline High school or less (reference) & 1 & & 1 & \\
\hline College & $0.43(0.23,0.80)$ & 0.007 & $0.34(0.16,0.70)$ & 0.003 \\
\hline Graduate or higher & $0.18(0.09,0.40)$ & $<0.001$ & $0.20(0.08,0.47)$ & $<0.001$ \\
\hline \multicolumn{5}{|l|}{ Marital status } \\
\hline Married/partnered (reference) & 1 & & 1 & \\
\hline Single & $2.57(1.50,4.40)$ & $<0.001$ & $1.52(0.77,3.00)$ & 0.25 \\
\hline \multicolumn{5}{|l|}{ Previous chemotherapy } \\
\hline No chemotherapy (reference) & 1 & & 1 & \\
\hline Chemotherapy & $0.50(0.29,0.86)$ & 0.01 & $0.81(0.40,1.63)$ & 0.55 \\
\hline \multicolumn{5}{|l|}{ Current aromatase inhibitor } \\
\hline None (reference) & 1 & & & \\
\hline Letrozole & $0.98(0.30,3.21)$ & 0.97 & & \\
\hline Anastrozole & $1.75(0.65,4.71)$ & 0.27 & & \\
\hline Exemestane & $1.14(0.32,4.05)$ & 0.84 & & \\
\hline \multicolumn{5}{|l|}{ Cormorbid conditions } \\
\hline None (reference) & 1 & & 1 & \\
\hline One & $1.14(0.44,2.97)$ & 0.78 & $1.11(0.34,3.49)$ & 0.88 \\
\hline Two or more & $2.06(0.88,4.83)$ & 0.10 & $1.71(0.57,5.05)$ & 0.34 \\
\hline \multicolumn{5}{|l|}{ Anxiety } \\
\hline Normal (reference) & 1 & & & \\
\hline Sympomatic & $0.92(0.49,1.70)$ & 0.79 & & \\
\hline \multicolumn{5}{|l|}{ Depression } \\
\hline Normal (reference) & 1 & & 1 & \\
\hline Symptomatic & $3.28(1.53,7.06)$ & 0.002 & $4.57(1.86,11.25)$ & $<0.001$ \\
\hline
\end{tabular}

*Mostly Black; hospital anxiety and depression scale (HADS) anxiety and depression categorization: normal = 0 to 7 ; symptomatic $=8$ to 21 . Covariates with $P$-values $<0.10$ in the univariate analyses were carried forward to the respective multivariate models. $P$-values in boldface type are statistically significant.

active [29-31]. In addition, race and depressive symptomotology were identified as significant risk factors for not engaging in physical activity. Targeted interventions to engage these sub-groups of breast cancer survivors, promote healthy lifestyles, and diminish risk of premature age-related disease and decline are a necessary next step.

Several limitations need to be considered. Firstly, a cross-sectional design seeks to identify an association 
rather than infer causation. Future prospective research needs to define the causal relationship between physical activity and TL. Secondly, the physical activity information was obtained via self-report, which has been shown to consistently lead to overestimation of physical activity and thus to underestimation of the effects of physical activity [32,33]. As such, the true effect of physical activity is probably even stronger than estimated. Lastly, our population was postmenopausal early-stage breast cancer, which may limit its generalizability to premenopausal women or those with more advanced cancer.

\section{Conclusion}

In summary, we found that TL was shorter in women with breast cancer who reported a sedentary lifestyle compared to those women who engaged in regular moderate to vigorous exercise, an effect that could not be explained by age. Future research needs to further define the causal relationship and uncover the mechanism of physical activity for enhancing cellular aging among breast cancer survivors.

\section{Abbreviations}

Adj $\beta$ : adjusted coefficient beta; AOR: adjusted odds ratio; bp: base pairs; BMI: body mass index; HADS: hospital anxiety and depression scale; IPAQ: international physical activity questionnaire; kb: Kilobase pairs; PBMC: peripheral blood mononuclear cells; TL: telomere length; TRF: terminal restriction fragment.

\section{Competing interests}

The authors declare that they have no competing interests.

\section{Authors' contributions}

$A D, C P$, and JJM conceived of the study and participated in its design and coordination. BJ and MD performed the telomere assays. SNG, RMS, SXX and JJM performed the statistical analyses and interpretation. SNG, RMS, and JJM drafted the manuscript. All authors read, edited, and approved the final manuscript.

\section{Acknowledgements}

This study was supported by a Penn Institute of Aging Pilot Grant. Sheila N Garland is a postdoctoral fellow funded by a Canadian Institutes for Health Research (CIHR) Bisby Fellowship. Jun J Mao is funded in part by grants from the National Center for Complementary and Alternative Medicine (K23 AT004112) and the National Cancer Institute (R01 CA158243). The content is solely the responsibility of the authors and does not necessarily represent the official views of the National Institutes of Health.

\section{Author details}

'Department of Family Medicine and Community Health, Perelman School of Medicine at the University of Pennsylvania, Philadelphia, PA 19104, USA.

${ }^{2}$ Abramson Cancer Center, Perelman School of Medicine at the University of Pennsylvania, Philadelphia, PA 19104, USA. ${ }^{3}$ Department of Pathology and Laboratory Medicine, Perelman School of Medicine at the University of Pennsylvania, Philadelphia, PA 19104, USA. ${ }^{4}$ Department of Family and Community Medicine, University of California San Francisco, San Francisco 94143, USA. ${ }^{5}$ Department of Anesthesiology and Critical Care, Perelman School of Medicine at the University of Pennsylvania, Philadelphia, PA 19104, USA. ${ }^{6}$ Center for Clinical Epidemiology and Biostatistics, Perelman School of Medicine at the University of Pennsylvania, Philadelphia, PA, USA.
Received: 16 December 2013 Accepted: 17 July 2014

Published: 31 July 2014

\section{References}

1. Siegel R, Naishadham D, Jemal A: Cancer statistics, 2012. CA Cancer J Clin 2012, 62:10-29.

2. Goh J, Kirk EA, Lee SX, Ladiges WC: Exercise, physical activity and breast cancer: the role of tumor-associated macrophages. Exerc Immunol Rev 2012, 18:158-176.

3. Schmidt ME, Chang-Claude J, Vrieling A, Seibold P, Heinz J, Obi N, Flesch-Janys D, Steindorf K: Association of pre-diagnosis physical activity with recurrence and mortality among women with breast cancer. Int J Cancer 2013, 133:1431-1440.

4. Ballard-Barbash R, Friedenreich CM, Courneya KS, Siddiqi SM, McTiernan A, Alfano CM: Physical activity, biomarkers, and disease outcomes in cancer survivors: a systematic review. J Natl Cancer Inst 2012, 104:815-840.

5. Andrews NP, Fujii H, Goronzy JJ, Weyand CM: Telomeres and immunological diseases of aging. Gerontology 2010, 56:390-403.

6. Lin J, Epel E, Blackburn E: Telomeres and lifestyle factors: roles in cellular aging. Mutat Res 2012, 730:85-89.

7. Du M, Prescott J, Kraft P, Han J, Giovannucci E, Hankinson SE, De Vivo I: Physical activity, sedentary behavior, and leukocyte telomere length in women. Am J Epidemiol 2012, 175:414-422.

8. Kim JH, Ko JH, Lee DC, Lim I, Bang H: Habitual physical exercise has beneficial effects on telomere length in postmenopausal women. Menopause 2012, 19:1109-1115.

9. Ludlow AT, Zimmerman JB, Witkowski S, Hearn JW, Hatfield BD, Roth SM: Relationship between physical activity level, telomere length, and telomerase activity. Med Sci Sports Exerc 2008, 40:1764-1771.

10. Lorenzini A, Johnson FB, Oliver A, Tresini M, Smith JS, Hdeib M, Sell C, Cristofalo VJ, Stamato TD: Significant correlation of species longevity with DNA double strand break recognition but not with telomere length. Mech Ageing Dev 2009, 130:784-792.

11. Craig CL, Marshall AL, Sjostrom M, Bauman AE, Booth ML, Ainsworth BE, Pratt M, Ekelund U, Yngve A, Sallis JF, Oja P: International physical activity questionnaire: 12-country reliability and validity. Med Sci Sports Exerc 2003, 35:1381-1395.

12. Puterman E, Lin J, Blackburn E, O'Donovan A, Adler N, Epel E: The power of exercise: buffering the effect of chronic stress on telomere length. PLOS One 2010, 5:e10837.

13. Johnson-Kozlow M, Sallis JF, Gilpin EA, Rock CL, Pierce JP: Comparative validation of the IPAQ and the 7-Day PAR among women diagnosed with breast cancer. Int J Behav Nutr Phys Act 2006, 3:7.

14. Bjelland I, Dahl AA, Haug TT, Neckelmann D: The validity of the Hospital Anxiety and Depression Scale: an updated literature review. J Psychosom Res 2002, 52:69-77.

15. Mitchell AJ, Meader N, Symonds P: Diagnostic validity of the Hospital Anxiety and Depression Scale (HADS) in cancer and palliative settings: a meta-analysis. J Affect Disord 2010, 126:335-348.

16. Slagboom PE, Droog S, Boomsma DI: Genetic determination of telomere size in humans: a twin study of three age groups. Am J Hum Genet 1994, 55:876-882.

17. Lin J, Epel ES, Blackburn EH: Telomeres, Telomerase, Stress, and Aging. In Handbook of Neuroscience for the Behavioral Sciences, Volume 3. Edited by Berntson GG, Cacioppo JT. New Jersey: John Wiley \& Sons, Inc; 2009:1280-1295.

18. Bojesen SE: Telomeres and human health. J Intern Med 2013, 274:399-413.

19. Duggan C, Risques R, Alfano C, Prunkard D, Imayama I, Holte S, Baumgartner K, Baumgartner R, Bernstein L, Ballard-Barbash R, Rabinovitch $P$, MCTiernan A: Change in peripheral blood leukocyte telomere length and mortality in breast cancer survivors. J Natl Cancer Inst 2014, 106:dju035.

20. Weischer M, Nordestgaard BG, Cawthon RM, Freiberg JJ, Tybjaerg-Hansen A, Bojesen SE: Short telomere length, cancer survival, and cancer risk in 47102 individuals. J Natl Cancer Inst 2013, 105:459-468.

21. Fontein DB, de Glas NA, Duijm M, Bastiaannet E, Portielje JE, Van de Velde CJ, Liefers GJ: Age and the effect of physical activity on breast cancer survival: a systematic review. Cancer Treat Rev 2013, 39:958-965.

22. Sanders JL, Newman AB: Telomere length in epidemiology: a biomarker of aging, age-related disease, both, or neither? Epidemiol Rev 2013. in press. 
23. Song Z, von Figura G, Liu Y, Kraus JM, Torrice C, Dillon P, Rudolph-Watabe M, Ju Z, Kestler HA, Sanoff H, Lenhard Rudolph K: Lifestyle impacts on the aging-associated expression of biomarkers of DNA damage and telomere dysfunction in human blood. Aging Cell 2010, 9:607-615.

24. O'Donovan A, Pantell MS, Puterman E, Dhabhar FS, Blackburn EH, Yaffe K, Cawthon RM, Opresko PL, Hsueh WC, Satterfield S, Newman AB, Ayonayon HN, Rubin SM, Harris TB, Epel ES, Health Aging and Body Composition Study: Cumulative inflammatory load is associated with short leukocyte telomere length in the health, aging and body composition study. PLoS One 2011, 6:e19687.

25. Woods JA, Vieira VJ, Keylock KT: Exercise, inflammation, and innate immunity. Immunol Allergy Clin North Am 2009, 29:381-393.

26. Tomiyama AJ, O'Donovan A, Lin J, Puterman E, Lazaro A, Chan J, Dhabhar FS, Wolkowitz O, Kirschbaum C, Blackburn E, Epel E: Does cellular aging relate to patterns of allostasis? An examination of basal and stress reactive HPA axis activity and telomere length. Physiol Behav 2012, 106:40-45.

27. O'Donovan A, Tomiyama AJ, Lin J, Puterman E, Adler NE, Kemeny M, Wolkowitz OM, Blackburn EH, Epel ES: Stress appraisals and cellular aging: a key role for anticipatory threat in the relationship between psychological stress and telomere length. Brain Behav Immun 2012, 26:573-579

28. Biegler KA, Anderson AK, Wenzel LB, Osann K, Nelson EL: Longitudinal change in telomere length and the chronic stress response in a randomized pilot biobehavioral clinical study: implications for cancer prevention. Cancer Prev Res (Phila) 2012, 5:1173-1182.

29. McNeill LH, Wyrwich KW, Brownson RC, Clark EM, Kreuter MW: Individual, social environmental, and physical environmental influences on physical activity among black and white adults: a structural equation analysis. Ann Behav Med 2006, 31:36-44

30. Pan SY, Cameron C, Desmeules M, Morrison H, Craig CL, Jiang X: Individual, social, environmental, and physical environmental correlates with physical activity among Canadians: a cross-sectional study. BMC Public Health 2009, 9:21-24.

31. Vidrine Jl, Stewart DW, Stuyck SC, Ward JA, Brown AK, Smith C, Wetter DW: Lifestyle and cancer prevention in women: knowledge, perceptions, and compliance with recommended guidelines. J Womens Health (Larchmt) 2013, 22:487-493.

32. Banda JA, Hutto B, Feeney A, Pfeiffer KA, Mclver K, Lamonte MJ, Blair SN, Vena J, Hooker SP: Comparing physical activity measures in a diverse group of midlife and older adults. Med Sci Sports Exerc 2010, 42:2251-2257.

33. Troiano RP, Berrigan D, Dodd KW, Masse LC, Tilert T, McDowell M: Physical activity in the United States measured by accelerometer. Med Sci Sports Exerc 2008, 40:181-188

doi:10.1186/s13058-014-0413-y

Cite this article as: Garland et al:: Physical activity and telomere length

in early stage breast cancer survivors. Breast Cancer Research 2014 16:413.

\section{Submit your next manuscript to BioMed Central and take full advantage of:}

- Convenient online submission

- Thorough peer review

- No space constraints or color figure charges

- Immediate publication on acceptance

- Inclusion in PubMed, CAS, Scopus and Google Scholar

- Research which is freely available for redistribution 